\title{
TRAFFIC MANAGEMENT OF MEGA INFRASTRUCTURE CONSTRUCTION PROJECTS: SUCCESS STORY AND LESSONS LEARNED FROM THE RIYADH METRO PROJECT
}

\author{
B. ALSHALALFAH ${ }^{1}$, J. NAFAKH ${ }^{2}$, Y. AL BANNA $^{3} \&$ I. KAYSI ${ }^{4}$ \\ ${ }^{1}$ Transport and Infrastructure Department, SETS International, Lebanon \\ ${ }^{2}$ Arriyadh Development Authority, Saudi Arabia \\ ${ }^{3}$ SETS International, Saudi Arabia \\ ${ }^{4}$ Department of Civil and Environmental Engineering, American University of Beirut, Lebanon
}

\begin{abstract}
The Saudi Arabian government is investing more than $\$ 22$ billion to build a metro system in Riyadh, with a total length of $176 \mathrm{~km}$ across 6 lines and 85 stations. The metro network has been under construction since 2013 and is expected to be in operation by 2019. One of the biggest challenges faced by the authorities early on is as to how to manage traffic during the construction period especially that the metro lines running along some of the busiest corridors in the city. Specifically, the construction of Metro Line 5 was expected to cause major disruptions due to several reasons, among them are significant traffic volume uses this main road; wide extent of construction works (very large worksites, undertaken at busy junctions); concurrent execution of other infrastructure projects in the vicinity; and the presence of more than 20 government entities along the road. In this regard, a Comprehensive Strategic Traffic Management Plan for Line 5 was developed based on the state-of-the-art traffic management practices, supplemented by innovative and outside the box concepts. The plan included physical measures such as converting major roads into temporary one-way roads, parking management, junction improvements, modifications to traffic signals as well as soft measures such as shifting working hours for some government entities and a very aggressive community outreach programme. The plan was implemented in 2015, and was well received by the general public in addition to the key stakeholders. This article presents the thinking behind the development of this plan - including a benchmarking exercise against projects of similar nature/scale, adopted methodology, challenges faced, expectations of the plans' performance before implementation as well as the results after the implementation of the plan. This successful story could be a good case study for forward thinking of managing traffic in mega infrastructure and urban transport projects.
\end{abstract}

Keywords: largest metro project, mega construction works, traffic management.

\section{INTRODUCTION}

Riyadh city is the capital of the Kingdom of Saudi Arabia and is one of the largest cities in the Middle East with a population of around 6 million, which is expected to grow to 9.5 million by the year 2025 [1]. Recent growth patterns and future forecasts indicate that Riyadh will have very high population growth rates, which will lead to an increase in the demand for travel on its roadway network and transportation system. The daily vehicle trips in Riyadh in 2015 were estimated to be over 7 million trips/day, with more than 100 million kilometres travelled daily [2]. Travel forecast models, developed and maintained by the authorities in Riyadh, revealed that the continuous growth of the city would result in more traffic congestion on the city road network, which could affect the economic viability and sustainability of the city if not addressed sooner than later.

Sensing this urgency, in 2011 the government of Saudi Arabia allocated a budget of more than $\$ 23$ billion to build a full metro network in Riyadh. The total length of the network is close to $176 \mathrm{~km}$ across 6 lines and 85 stations [3], covering most of the city of Riyadh, linking 


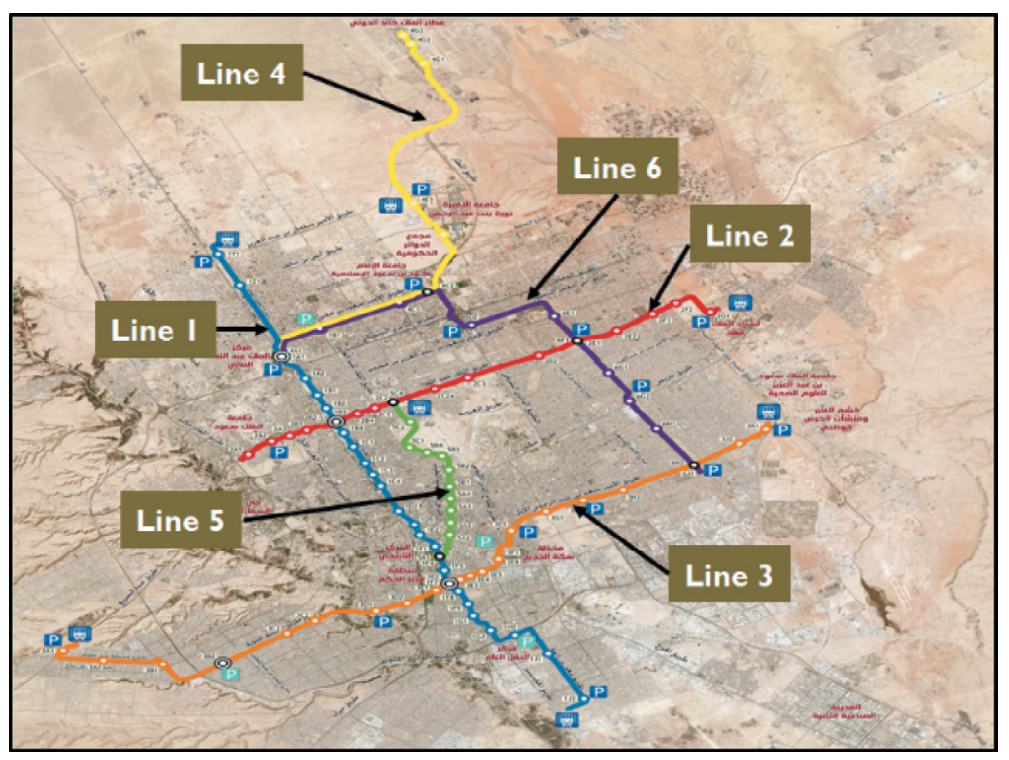

Figure 1: Riyadh metro lines.

the city centre to universities, the international airport, a newly built financial district and major commercial areas as shown in Fig. 1.

The metro project, along with a planned multilevel bus network, constitutes the very ambitious and aggressive Riyadh Public Transport Program (RPTP). The programme, which is managed by the Arriyadh Development Authority (ADA), aims at providing feasible and diverse mobility options for people in the city of Riyadh.

The metro project is likely the largest urban transport project in the world during its construction programme, incurring a lot of pressure on the city infrastructure and operation during the construction phase. Construction of the project started in 2013 and is planned to be completed by 2020 .

The construction and delivery of the metro project was awarded to three different designbuild contractors (DBC) as follows:

- Package 1: BACS consortium was awarded the design and build (DB) of lines 1 and 2 with a total length of $63.3 \mathrm{~km}$ of network.

- Package 2: Arriyadh New Mobility consortium was awarded the DB of line 3 with a total length of $40.7 \mathrm{~km}$.

- Package 3: FAST consortium was awarded the DB of the remaining three lines (lines 4, 5 and 6), covering a total length of $72.5 \mathrm{~km}$.

To facilitate the interaction between the owner of the project (ADA) and the DBCs, two project management/construction management (PMCMs) teams were retained by the ADA as the owner representative and to act as the interface between DBCs and the ADA. The organizational chart of the RPTP, as described earlier, is presented in Fig. 2. 


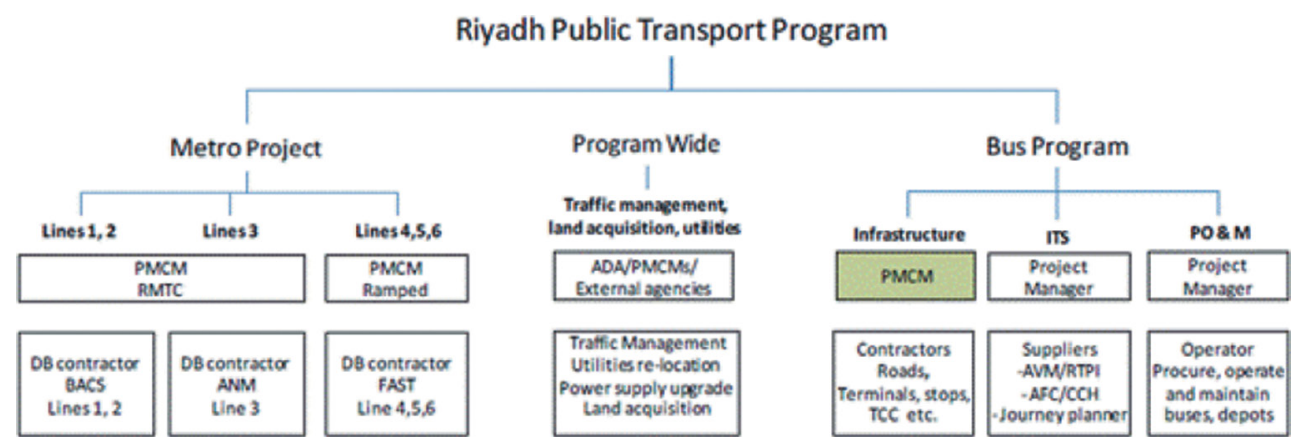

Figure 2: Organizational chart of the Riyadh Public Transport Program.

Due to the very tight and demanding construction schedule of the Riyadh metro and the fact that many construction activities affecting the roadway network are going to take place at the same time, there was a great focus on traffic management during construction to keep the city moving. As such, and to ensure the smooth implementation of the project and to minimize the adverse impacts on traffic conditions in the city during the metro construction phase, each DBC and each PMCM were required to hire traffic management consultants to develop traffic management schemes under which each metro line will be constructed. The foremost objective of these schemes is to minimize the adverse impacts on traffic conditions in the city during the construction period. Specifically, the construction of Metro Line 5 (running along King Abdulaziz Road (KAAR) in the heart of the city - see Fig. 3) was expected to cause major disruptions due to many reasons, which will be discussed later in this article.

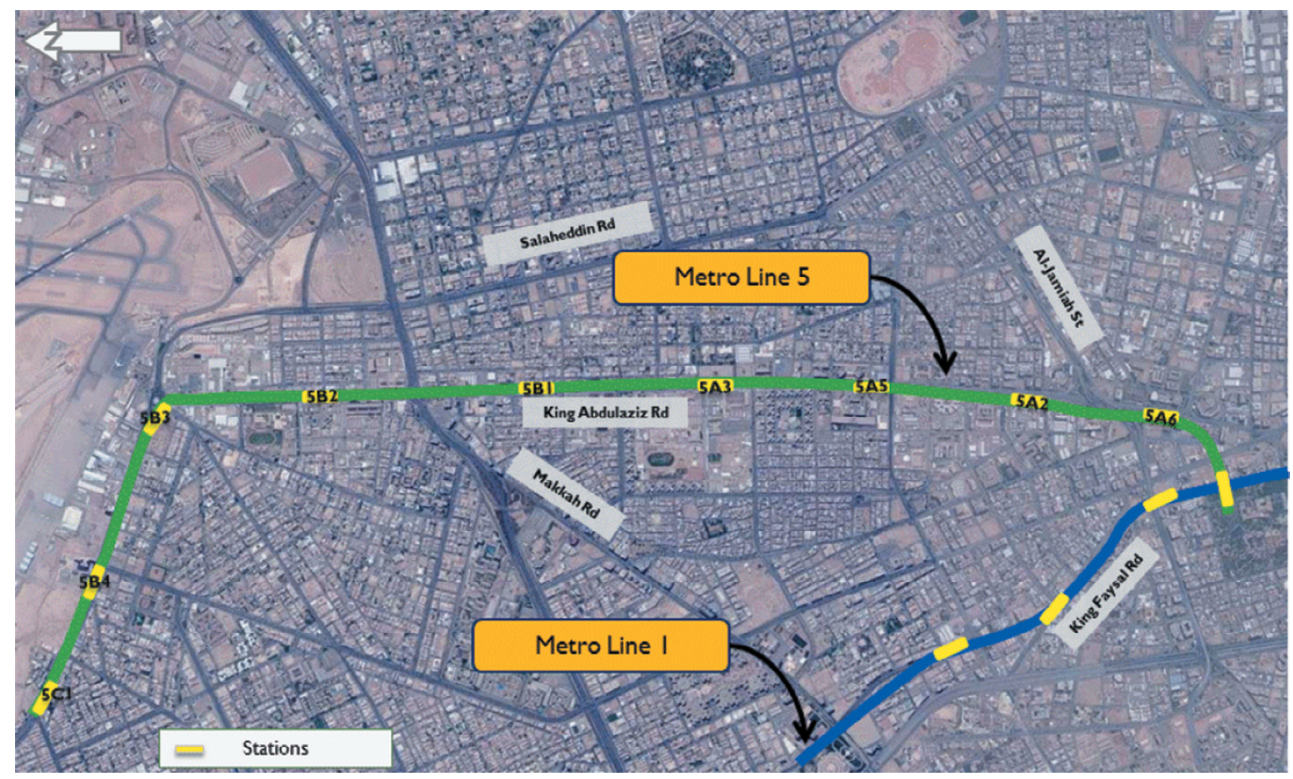

Figure 3: Metro Line 5 alignment and stations. 
Therefore, a Comprehensive Strategic Traffic Management Plan for Line 5 was developed based on the state-of-the-art traffic management practices, supplemented by innovative and outside the box thinking. The plan was gradually implemented in 2015 with great success and was well received by the general public in addition to key stakeholders.

This article presents the thinking behind the development of this plan, the process followed, challenges faced, adopted methodology, plans' performance before implementation as well as the results after the implementation of the plan. This success story could be a good case study for forward thinking of managing traffic in mega infrastructure and urban transport projects.

\section{LITERATURE REVIEW}

One of the requirements of the project is for each DBC to prepare their own traffic management plans (TMPs) and associated temporary traffic control plans (TTCPs) for each metro line in their package. This includes analysing and establishing the traffic management constraints and conditions under which each metro line will be constructed. In addition, each PMCM was required to hire a traffic management team (TMT) that would be responsible for reviewing, advising and approving TMPs and TTCPs submitted by the DBs to make sure these submissions and plans are consistent with the relevant and applicable policies and procedures.

Given the unprecedented and uncommon scale of the construction works ( $180 \mathrm{~km}$ of routes, 85 stations), it was essential before embarking on developing TMPs for this mega project to put into context all conditions, constraints, opportunities and best practices that relate to traffic management during construction, and especially those that would help in the case of Riyadh. In this context, the definition of what a 'construction work zone' or 'construction area' refers to was a key issue to deal with early on, given the local conditions associated with this project. Several definitions can be found in the literature, such as the one by Karim and Adeli [4] where they defined a work zone as 'a region within an existing highway's roadway where active maintenance, rehabilitation, and/or reconstruction work is carried out'. Other definitions that are more applicable to the case of Riyadh is the one provided by HCM 2000, which defines a work zone as 'a segment of highway in which maintenance and construction operations impinge on the number of lanes available to traffic or affect the operational characteristics of traffic flowing through the segment'. Since the traffic impact of the construction work zones of the Riyadh metro project was expected to far exceed the area delimited by construction activities, it was concluded that the definition provided by HCM 2000 is more applicable to the case of Riyadh.

From that perspective, the TMT not only reviewed international best practices in the area of traffic management during construction works specifically but also looked at traffic management concepts in general (i.e. those measures and schemes that are typically used to solve severe traffic congestion problems - in mega events - not necessarily during construction). In addition to that, the team reviewed relevant standards/manuals, so as to learn from these resources and try to benefit from them in the context of the Riyadh metro project.

In terms of traffic management in mega events, the team reviewed the traffic measures adopted in the Olympic Games that were held in London in the summer of 2012, which attracted millions of athletes, spectators and tourists. At the transportation system/traffic management level, in addition to several traffic management schemes, the Olympic Park was served by a dedicated rail shuttle service, called the Olympic 'Javelin', which was designed to transport 25,000 spectators per hour [5,6]. The team also reviewed the traffic management schemes that were implemented in the 2010 World Cup in South Africa [7, 8], and the 2008 Beijing Olympics [9-12]. 
In terms of traffic management during construction, several TMPs from around the world were reviewed, varying in scale and context. Some of the reviewed studies included TMP for the construction of Foxground and Berry Bypass (FBB) in NSW, Australia [13], which describes how to safely manage vehicular, cyclists and pedestrian traffic during the design and construction phase of the FBB project; TMP for the construction of MacKays to Peka Expressway Project in New Zealand, which is a $16 \mathrm{~km}$ new expressway [14]; and project TMP for the construction of the Port Botany Expansion Project in Sydney, Australia [15]. The knowledge gained from reviewing those resources helped in forming a better understanding of the approach that should be followed towards addressing the traffic impacts associated with Riyadh metro.

\section{THE PROCESS}

In the case of Metro Line 5, from the beginning it was realized by the Client, PMCM and the DBC that the traffic challenges on this specific metro line would require a collaborative team effort rather than a PM/contractor relationship. Therefore, the traffic teams of both the PMCM and the DBC worked as a cohesive unit to come up with an agreed-on, well-studied TMP for Line 5. In this respect, the combined traffic team followed a clear and sequential process as follows:

1. Developing an understanding of the project's and Line 5 traffic and transport issues, challenges and opportunities

2. Developing a TMP for Line 5 (including a logistics plan) and associated TTCPs

3. Managing the implementation of the TMP and TTCPs

4. Managing any updates to the TMP and TTCPs (whenever future updates of the TMP occur)

Throughout the process, liaison and coordination with all stakeholders, including DB construction team, client, relevant stakeholders and other metro/bus packages, was an essential activity of the entire effort.

\section{DEVELOPMENT OF LINE 5 TRAFFIC MANAGEMENT PLAN}

\subsection{General concepts}

In coordination between the PMCM and DB traffic teams, a TMP for Line 5 was prepared. The plan sets out, among other items, the overall project timetable, construction methods, proposed major traffic management schemes (TTCPs) anticipated and initial logistics plan. The information provided in the TMP identified what constraints may need to be applied in terms of construction timing or method, where it has a bearing on traffic management. The TMP also identified hard and soft mitigation measures that may be required to mitigate the expected adverse traffic impacts.

Throughout this process, the traffic team was in continuous coordination and liaison with both the client (ADA) and the construction team to make sure that both parties fully understand the requirements of the elements of the traffic management plans developed by the traffic team to avoid any disruptions.

The TMP sets out the following traffic impact assessment procedure to be followed in developing the alternatives for traffic management schemes:

- Step 1 - Define study area and site appraisal

- Step 2 - Define traffic surveys' work 
- Step 3 - Analyse Existing Traffic Conditions

- Step 4 - Traffic modelling work

- Step 5 - Analyse impact of construction works on area of influence of project site

- Step 6 - Develop mitigation measures.

\subsection{The challenge}

From the start, it was clear to everyone that the construction of Metro Line 5 was expected to cause major disruptions to the traffic patterns in and around KAAR due to the existing significant traffic volume and congestion on the road, since it is one of the major corridors in the city. In addition, the number of underground stations is significant on this line which would lead to very large worksites along the road, and the closure of very busy junctions on the roadway network during the construction phase. The effect of this construction work is compounded by the presence of concurrent metro and other infrastructure projects in the vicinity. Metro line ' 5 ' is shown in Fig. 4.

Therefore, it was understood that a solid start-up process with the key parties involved in this project (PMCM teams, TMC, DB contractors and other stakeholders), as well as a common understanding of the project requirements, relationships, inter-dependencies, communication channels, activities and the expected outcomes should be achieved. Taking into consideration the significant size of this project, the initial period of the project was dedicated by the traffic team to gain a clear and comprehensive understanding and appreciation of the project, including:

- understanding the project site(s), constraints, size and magnitude;

- understanding the roles, responsibilities and requirements of the DB contractors, PMCMs as well as other stakeholders;

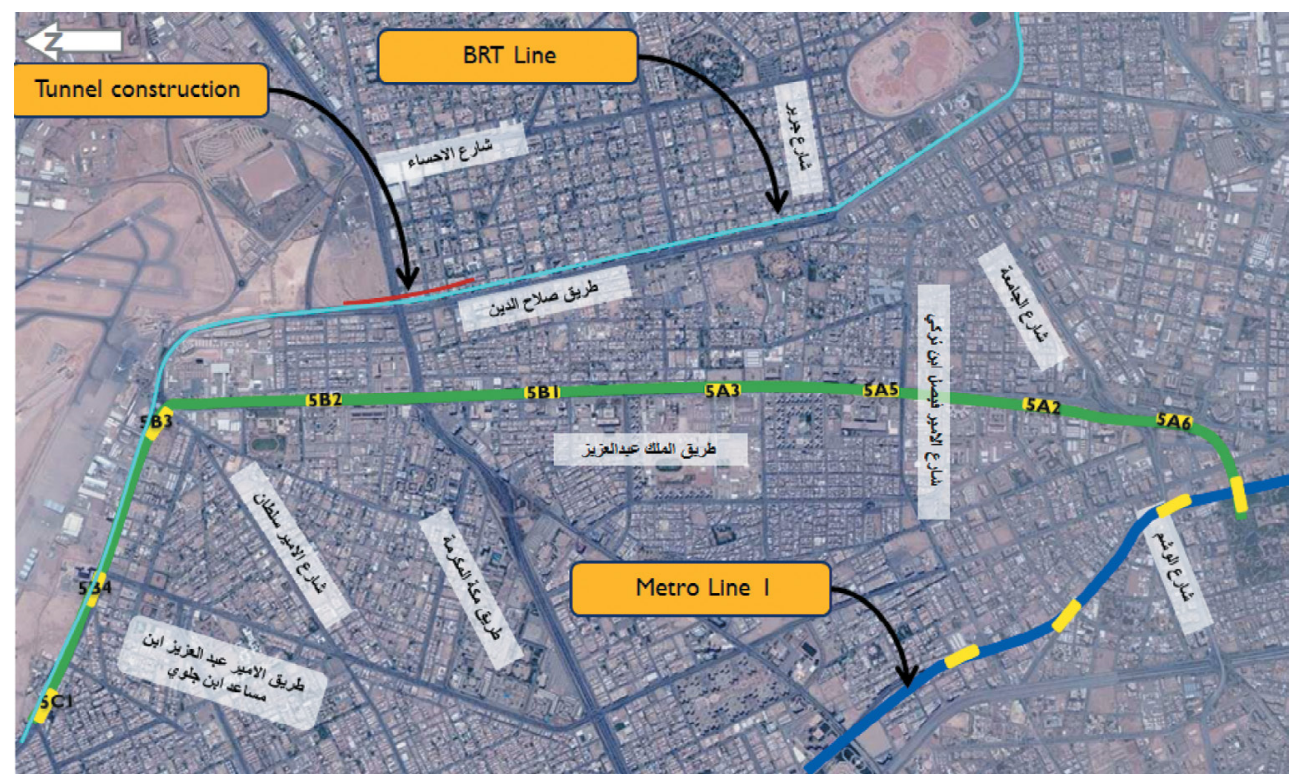

Figure 4: Line 5 traffic challenges. 
- understanding the main implicit and explicit relationships between project milestones and their impact on the traffic management schemes;

- understanding of the key stakeholders that may be affected by the construction works. In this respect, all major stakeholders along the alignment of the line were identified, which included the headquarters of around 10 ministries (Ministry of Defence alone have more than 15 facilities other than its headquarters).

Overall, this phase involved the following activities:

- Review of project documents and background material: the aim of this activity was to review all available project documents as well as background material (such as project background and overview, information on other concurrent projects in Riyadh, etc.) in order for the traffic team to acquaint itself with the project and its anticipated volume of work.

- Site reconnaissance: site visits were conducted by the traffic team to acquaint itself with the project sites and to record observations related to traffic that might be of interest during project implementation.

- Coordination and liaison: this was a key activity that started early in the process and continued throughout the project implementation period with all key stakeholders, especially the public and private entities affected by the construction works along Line 5 .

\subsection{The opportunity}

To develop the traffic management plan during the construction phases, the focus was on better utilization of the surrounding roadway network. This was mainly due to the travellers' behaviour which preferred using the main roads to the surrounding local roads even if this was associated with more travel delays. The Riyadh Strategic Model (developed using EMME software) was used for this purpose to better understand the impact of construction works of Line 5 on the surrounding areas. The aim was to assess and validate the traffic flow changes that are expected to occur as a result of the construction works and associated closures. This is illustrated in Fig. 5, extracted from the Riyadh Strategic Model, which shows the peak AM V/C along KAAR and the surrounding secondary roadway network.

The effect of the construction works on the operating conditions and the traffic volumes/ patterns on the surrounding network were modelled using the EMME software and the results are shown in Fig. 6. The results show that traffic is naturally diverted to parallel and adjacent roads when the closures at station locations on KAAR are imposed. The roads where traffic was diverted were identified as the candidates for further study and analysis to improve their performance to accommodate the diverted traffic from KAAR. Not only that, but this early exercise enabled the team to define a clear study area for Line 5 TMP that is bounded by the main roads affected, as shown in Fig. 7.

\subsection{Traffic surveys and site appraisal}

In addition to the site appraisal programme (not discussed here due to lack of space), traffic count data were collected on the links and junctions within Line 5 study area as shown in Fig. 8. The existing traffic volumes were obtained based on a programme of traffic counts and road inventory surveys that were conducted prior to the commencement of construction works. The data collected included: 


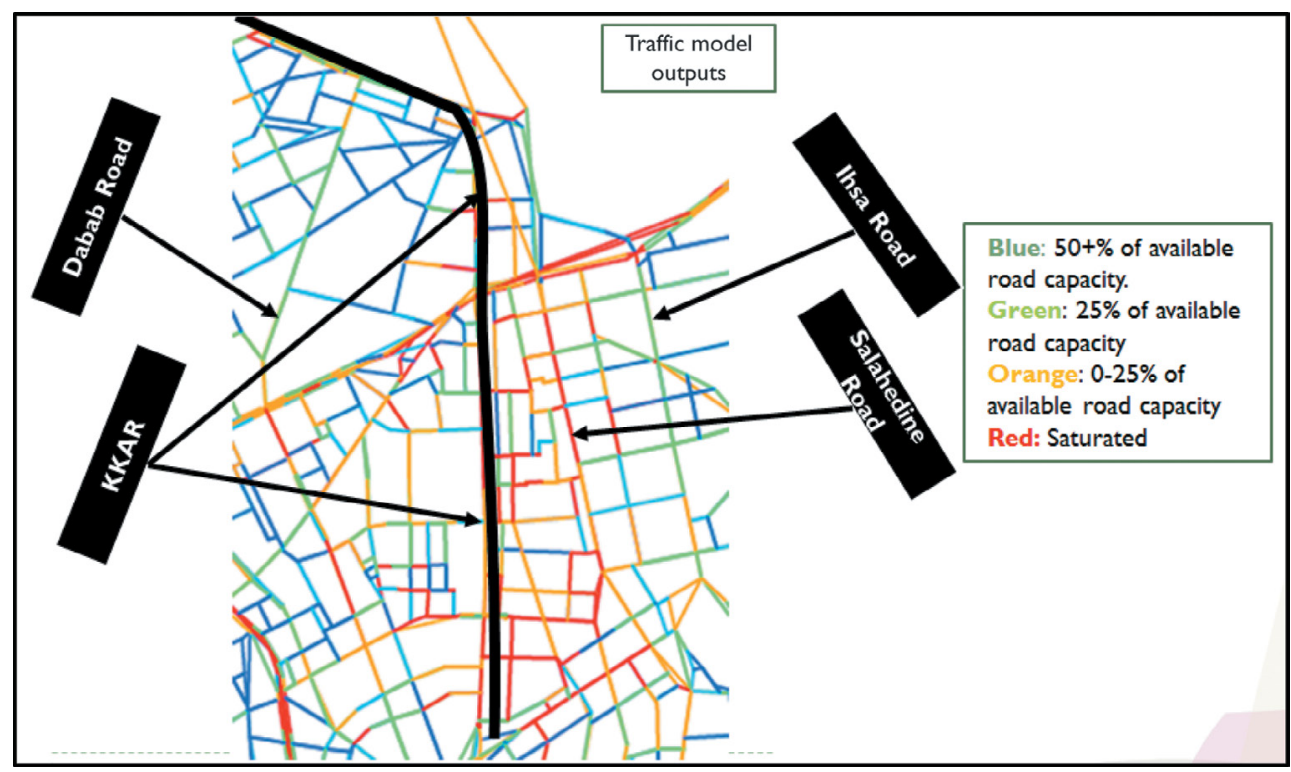

Figure 5: Line 5 strategic model output.

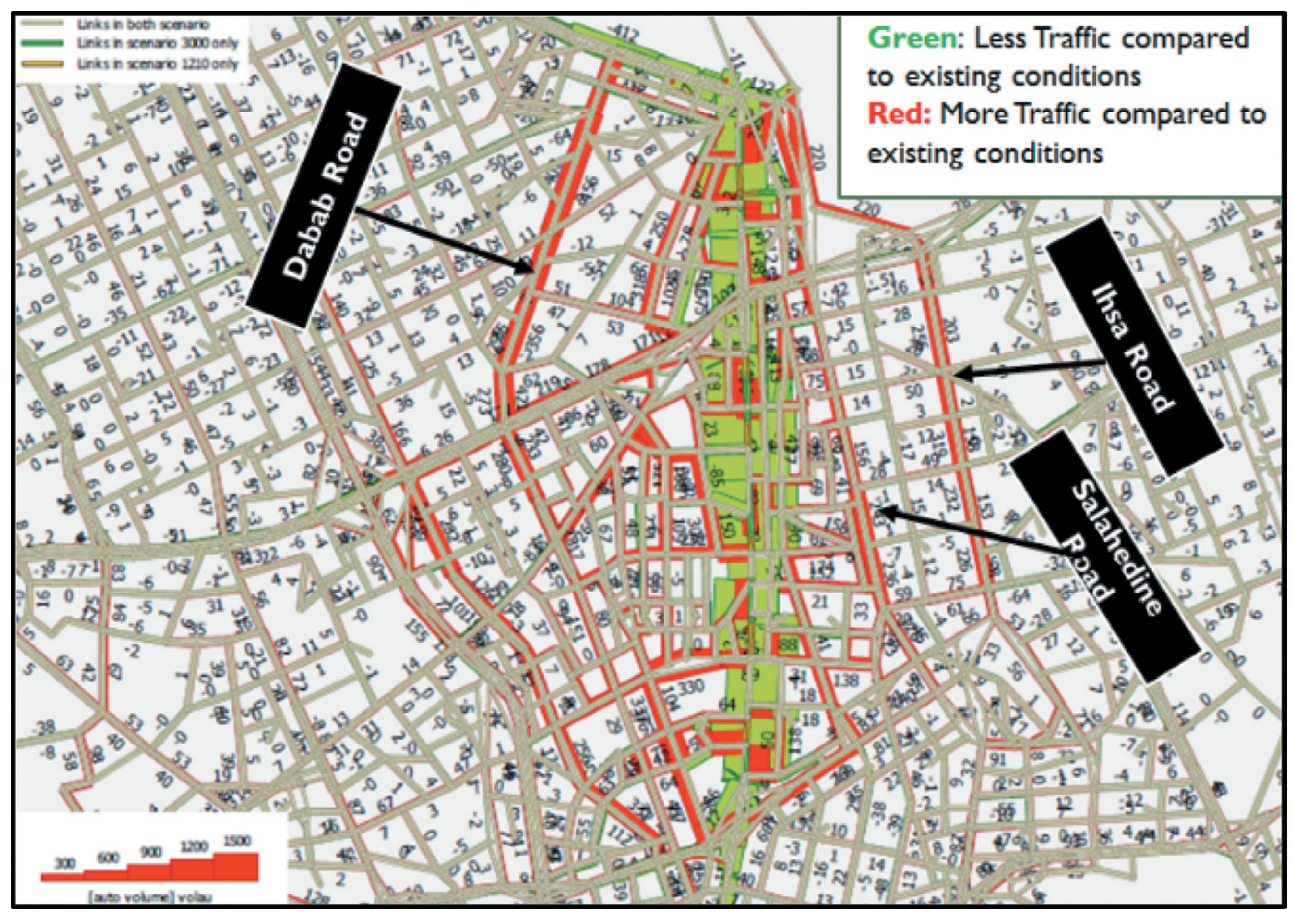

Figure 6: Impact of construction activities on traffic patterns. 


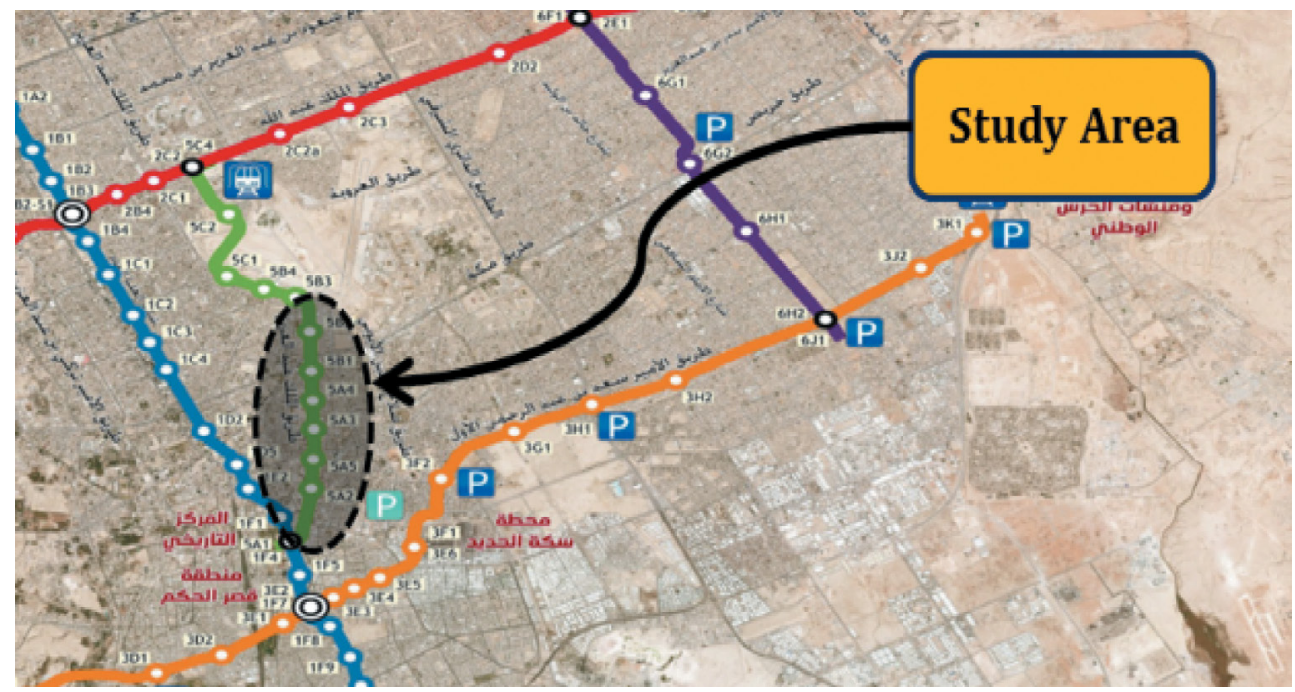

Figure 7: Line 5 study area.
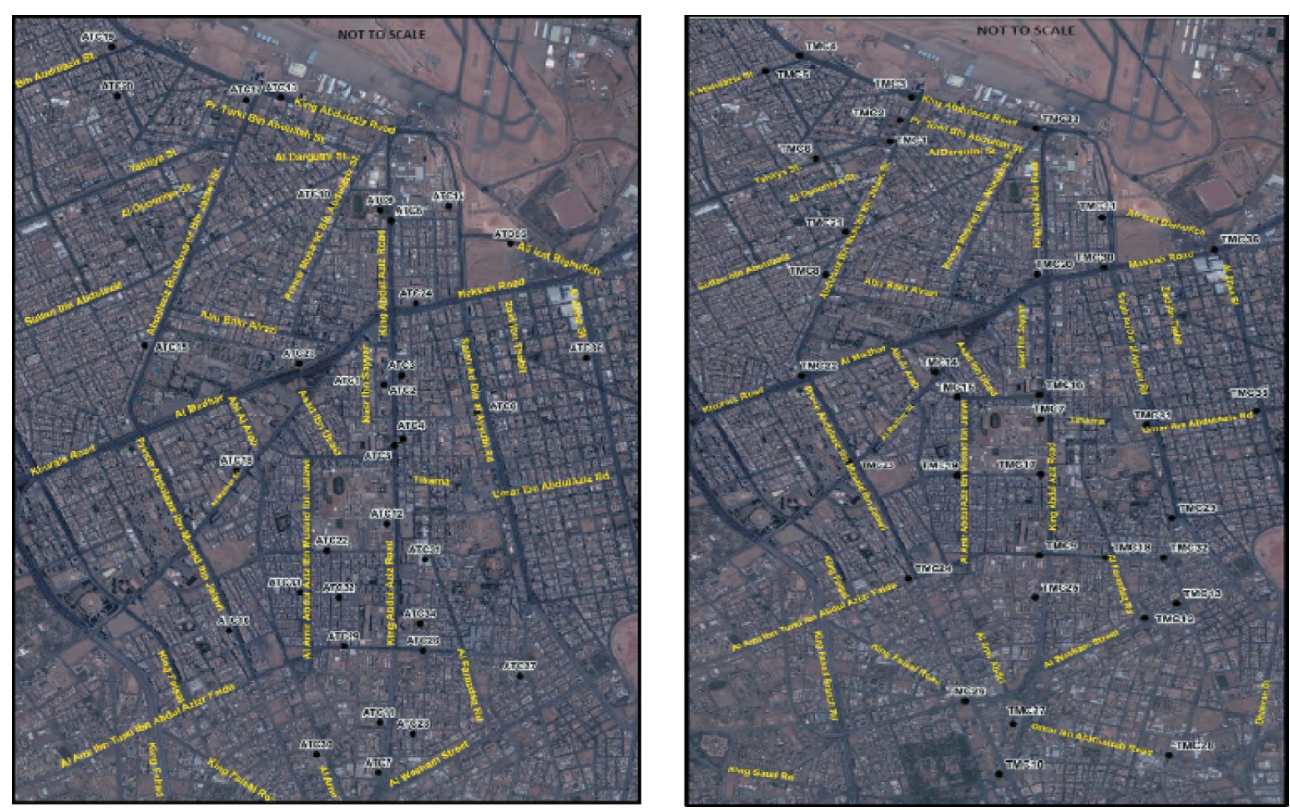

Figure 8: ATC and TMC location on Line 5 subarea.

- Thirty-five locations of automatic traffic count (ATC) with vehicle classification (heavy or light vehicles) and continuous 24 -h data collection.

- Thirty-five locations of turning movement counts (TMC) with vehicle classification as well.

Moreover, a traffic signal survey was carried out in the whole subarea network, checking the allowed movements, cycle time, phases, etc. Based on these times and the TMC counts, the 


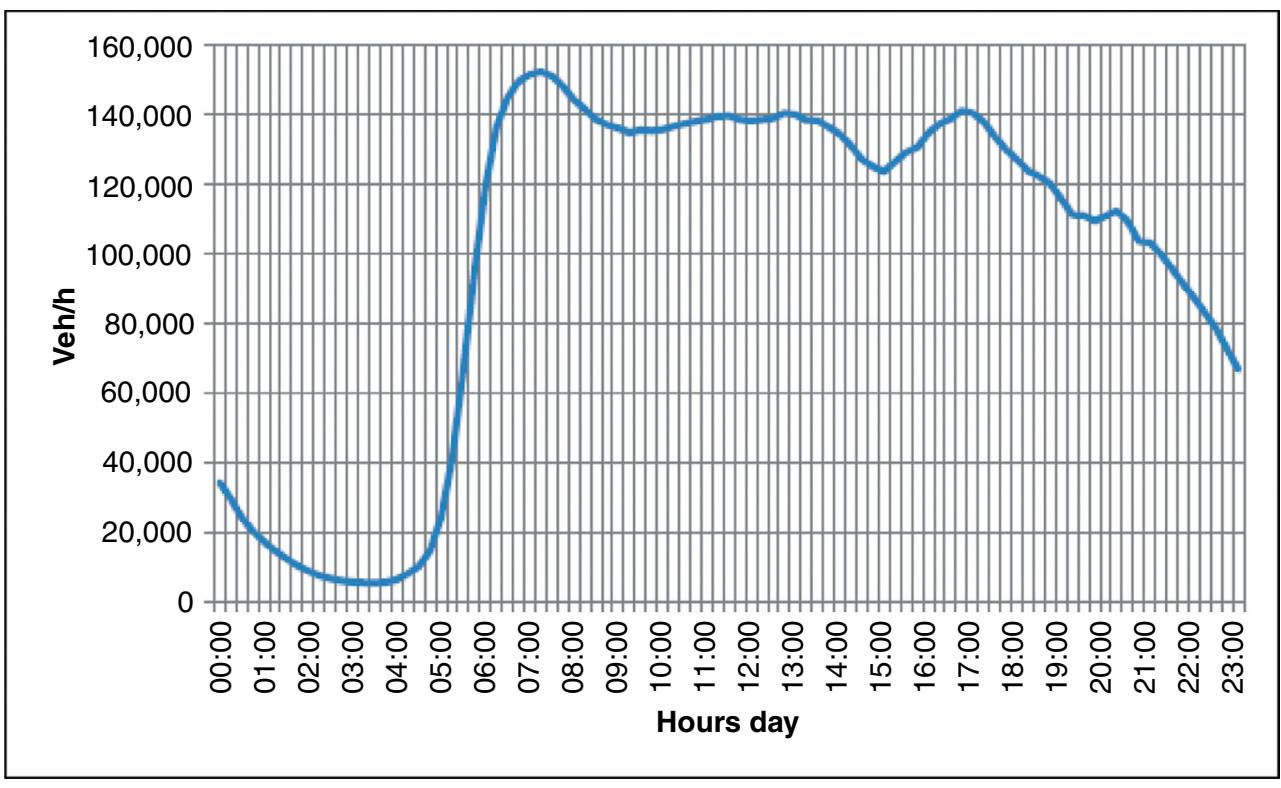

Figure 9: Daily traffic profile from ATC counts.

existing conditions on the road network and affected junctions were extracted. Based on collected traffic counts data, the peak hours were identified as 7.15-8.15 am and 16.45-17.45 pm. Figure 9 shows the traffic profile during $24 \mathrm{~h}$ based on free-flow conditions from ATC.

\subsection{The approach and strategy}

During the development of Line 5 traffic management plan, the focus was on minimizing (to the extent possible) the impact of the construction activities on the roadway network operating conditions, while ensuring the smooth implementation of the project (on time and within budget). Due to the demanding work schedule, it was concluded that a Single Comprehensive Traffic Management plan needs to be developed during the period of construction of Line 5 to minimize confusion and disturbance to citizens caused by frequent changes to traffic schemes. The strategy took into consideration the following:

- The plan integrated other infrastructure activities in the area and diverted traffic to parallel unutilized roads.

- Where possible, relocate construction activities away from the road network (such as Tunnel Boring Machine (TBM) shafts).

- Regional (i.e. through) journeys should be diverted away from KAAR via parallel highcapacity roads (i.e. strategic diversion routes).

- Provide local diversion schemes to maintain accessibility to KKAR.

- Maintain accessibility to all facilities along KKAR.

- Identify potential mitigation tools.

- Ensuring safety for all users at all times. 


\subsection{The mitigation measures}

The traffic team identified a set of possible mitigation measures that have the potential to minimize the negative impacts of construction in order to achieve an acceptable performance of the road network during the construction period. These mitigation measures include the following:

- 'Hard' physical measures that are aimed at providing improvements to road capacity, or at the very least smooth traffic flow around construction work areas through the introduction of temporary fixed elements that do not change frequently.

- 'Soft' management measures that are aimed at managing (or even suppressing) the demand for travel and may include more dynamic schemes to manage traffic and/or travel habits.

A number of hard measures were contemplated; some of the key measures included:

- Temporary bridges:

- Along station construction boxes

- Along relief roads

- Road capacity enhancements

- Temporary one-way roads

- Junctions improvements

- Modifying and/or removal of parking

- New U-turns to replace banned left turns

- Traffic signals:

- New traffic signals

- Modifications to existing traffic signal timings (coordinated signals, Green Wave, signal optimization, etc.)

The 'hard' measures were contemplated on a site-by-site basis, and after having undertaken site visits to assess the traffic conditions and site constraints in all areas affected by construction. All the hard mitigation measures were used except the temporary bridges, which were not feasible at the identified locations due to more than one factor (impact on construction activities, time requirements, etc.).

As for 'Soft' measures, the objective is the promotion and provision of measures aimed at decreasing the levels of traffic volumes and movement patterns in the peak hours to cause a reduction in the use of the private car or to encourage people (by providing them with relevant information on a timely basis) to follow a specific pattern of movement in a way that results in balanced distribution of travel around the city. The identified soft measures included:

- Flexible or staggered working hours to reduce congestion at peak times. Those can be specific to schools and government authorities.

- Providing traveller information tools, including intelligent transportation system improvements, mobile and social applications and other methods.

The flexible or staggered working hours' proposal was dropped by the authorities due to several legal issues that would have made it very hard to obtain approvals on such measures from government authorities. The only 'soft' measure that was implemented is the launching 
Table 1: Performance of selected TMP.

\begin{tabular}{lcl}
\hline KPI & Base conditions & Selected plan \\
\hline Delay time $(\mathrm{s} / \mathrm{km})$ & 214.11 & $183.6(-15 \%)$ \\
Flow $(\mathrm{veh} / \mathrm{h})$ & 76,328 & 78,256 \\
Stop time $(\mathrm{s} / \mathrm{km})$ & 192.41 & $158.94(-18 \%)$ \\
Travel time $(\mathrm{s} / \mathrm{km})$ & 264.91 & $235.2(-11 \%)$ \\
\hline
\end{tabular}

of a mobile application (called Delilat Arriyadh), similar in functionality to Google Maps, where all metro traffic management schemes and detours were updated very frequently so that users could use this application to choose their routes.

\subsection{The final traffic plan}

After testing several iterations of different concepts and proposals using the traffic model, a final TMP for Line 5, which achieved the best performance, was adopted. The process of the plan development also included hundreds of coordination meetings and workshops with stakeholders ranging from ADA top management, traffic police, Ministry of Transport and government officials to local businesses and residents. The success of the plan is mainly related to an exhaustive and extensive effort by the traffic team, supported by the endorsement of the client (ADA) to get everyone involved on-board with the plan.

Table 1 presents the traffic analysis results of the adopted plan in comparison to the base conditions. Surprisingly, the overall traffic performance of Line 5 TMP exceeded the base conditions. This was one of the big achievements of this plan, whereby optimizing the road network resulted in a better performance of the road network even with a closure of one major arterial in the city.

Figure 10 presents the overall traffic management plan for Line 5 that was implemented on site.

\subsection{Observations after implementation}

After implementing all components of the plan, all parties involved agreed that the plan outperformed expectations, especially with travellers getting familiar with the new traffic management arrangements faster than expected. In fact, there have already been some calls to keep some of the implemented traffic management schemes to be long term after the completion of the construction works due to the improved performance and accessibility in some areas of the study area.

\section{SUMMARY AND CONCLUSIONS}

The Saudi Arabian government is investing more than $\$ 22$ billion to build a six-line, $176 \mathrm{~km}, 85$-stop metro system in the capital city of Riyadh. One of the biggest challenges that were identified early on is as to how to manage traffic in the city during the construction period especially that all six metro lines run along busy corridors. One of the most critical lines is Metro Line 5 along KAAR in the heart of the city. The construction of this line was anticipated to cause major disruptions due to the significant traffic volume using this major arterial road, the large construction works required at main junctions as well as the 

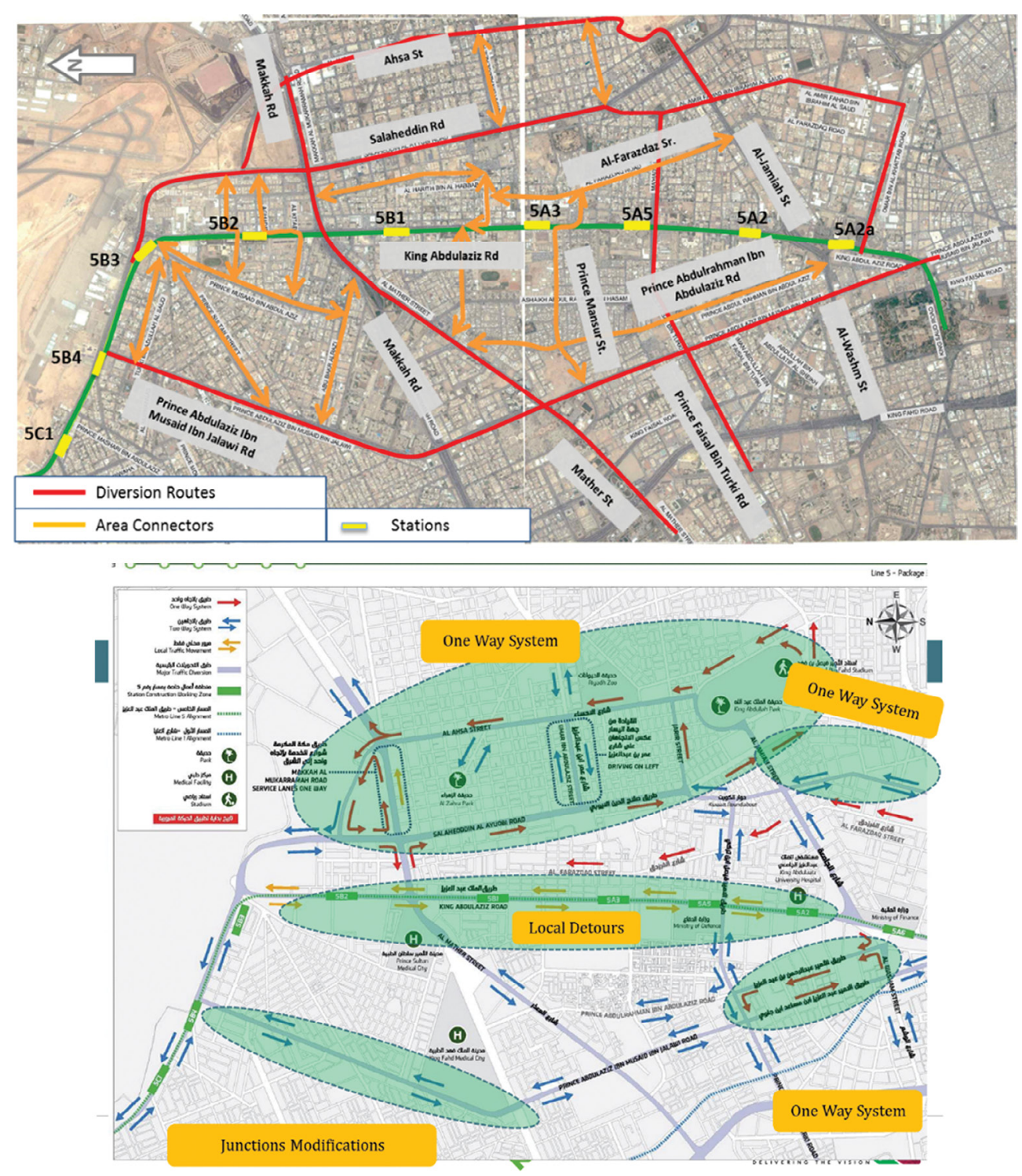

Figure 10: Line 5 final traffic management plan.

concurrent execution of other infrastructure projects in the vicinity of the road. The traffic team responsible for this line developed a Comprehensive Strategic Traffic Management that addressed the challenges, optimized opportunities and used state-of-the-art traffic management practices supplemented by innovative and outside the box concepts. The plan included aggressive physical measures such as converting major roads into temporary one-way roads, improvements to traffic flow and a very aggressive community outreach programme. The plan was implemented in 2015 with great success and is expected to stay throughout the project duration. 
The success of the plan depended largely on combining local knowledge of the city traffic conditions, using proven traffic modelling approaches to guide the thinking process, proposing aggressive mitigation measures to minimize the impact of the project with such a large size, and managing a large number of stakeholders efficiently and concurrently. This successful story could be a good case study for forward thinking of managing traffic in mega infrastructure and urban transport projects.

\section{ACKNOWLEDGEMENTS}

This article is the result of a collaborative effort of everyone involved in the construction of Line 5 of the Riyadh Metro Project, from the top management of the ADA to the field engineers working daily on site.

\section{REFERENCES}

[1] General Authority for Statistics, Saudi Arabia, available at https://www.stats.gov.sa/en (accessed 23 April 2017).

[2] Riyadh Municipality, Saudi Arabia, available at https://www.alriyadh.gov.sa/en (accessed 23 April 2017).

[3] Riyadh Metro Project Website, Saudi Arabia, available at http://riyadh-metro.com (accessed 23 April 2017).

[4] Karim, A. \& Adeli, H., Radial basis function neural network for work zone capacity and queue estimation. Journal of Transportation Engineering, 129(5), 495-496, 2003. DOI: 10.1061/(ASCE)0733-947X(2003)129:5(494).

[5] House of Commons Transport Committee, Transport for the London 2012 Olympic and Paralympic Games: The Draft Transport Plan: Olympic Delivery Authority Response to the Committee's Third Report of Session 2006-07, 2007.

[6] London Olympics Transport Upgrade, available at http://www.railway-technology. com/projects/london-olympics/ (accessed January 2014).

[7] Bus Rapid Transit System [BRT] and Road Safety, available at http://www.arrivealive. co.za/pages.aspx ?i=2874 (accessed January 2014)

[8] South Africa.info, available at http://www.safrica.info/business/economy/infrastructure/ transport.htm (accessed December 2013).

[9] Beijing Olympic Village Rail Link Construction, Railway-technology.com, available at http://www.railway-technology.com/projects/beijing-metro/ (accessed December 2013).

[10] Amos, A., Bullock, D. \& Sondhi, J., High-Speed Rail: The Fast Track to Economic Development? China: The World Bank, 2010.

[11] Yukun, J., Analysis on Beijing subway flows during the 29th Olympics. Journal of Transportation, Systems Engineering and Information Technology, 8(6), 46-51, 2008.

[12] Mingjun, L., Baohua, M., Yu, H., Jianpeng, Z. \& Shaokuan, C., Comparison of pre- \& post-Olympic traffic: a case study of several roads in Beijing. Journal of Transportation, Systems Engineering and Information Technology, 8(6), 67-72, 2008. DOI: 10.1016/ S1570-6672(09)60002-7.

[13] Fulton Hogan, Construction Traffic Management Plan, Project: Foxground and Berry Bypass, 2014.

[14] NZ Transport Agency, Construction Traffic Management Plan, Mackays to Peka Peka Expressway, 2013.

[15] Baulderstone Hornibrook, Project Traffic Management Plan for Design and Construction of the Port Botany Expansion Project, 2008. 